\title{
La aplicación de la Ley de la Dependencia en el País Valenciano y su vínculo con el Estado del bienestar: valoraciones a partir del caso del área metropolitana de València ${ }^{1}$
}

\section{Óscar Muñoz González}

Facultat de Ciències Socials, Universitat de València

<osmugon@gmail.com>

\section{Josep V. Pitxer i Campos}

Departament d'Economia Aplicada, Universitat de València

Testu honetan burutzen da Mendekotasun Legea ezarri zenetik Valentziako Herrialdean hamar urteotako balantze bat, eta horretarako oinarri hartzen da testu legal horrek ezarpen oso eskasa egin duenaren hipotesia eta eragin dien pertsonek izandako kalte nabarmenak. Hamaika berriemaile garrantzitsurekin eginiko elkarrizketa eta metodologia kualitatibo batean oinarrituz, ondorioztatzen da Administrazioak bete duen rola izan dela funtzio eta ardurak albo batera uztea, eta beste aktore protagonista batzuen -familia, merkatua eta hirugarren sektorea- garrantzia berriz egokitzera behartzea. Gainera, hirugarren sektoreko erakunde batzuk zailtasun nabarmenak dituzte aztertutako kolektiboarentzat zaintzarako zerbitzuak eskaintzean enpresa kapitalistekin lehiakor izateko, eta mendekotasunaren arretarako premiak betetzeko ez dituzte aukera berberak izaten erakunde horiek guztiek.

\section{GAKO-HITZAK:}

Mendekotasun Legea, hirugarren sektorea, gizarte-zerbitzuak, ongizatearen Estatua, herstura ekonomikoko politikak.
El presente texto ofrece un balance de la aplicación de la Ley de la Dependencia en el País Valenciano tras cerca de diez años desde su aprobación, partiendo de la hipótesis de una muy deficiente aplicación del texto legal, con perjuicios notables para las personas afectadas. A partir de una metodología cualitativa, con once entrevistas a informantes clave, se concluye que el papel desempeñado por la Administración se caracteriza por un vaciado de sus funciones y responsabilidades en favor del resto de actores protagónicos

-familia, mercado y tercer sector- y el consiguiente recalibrado de la importancia de cada uno de ellos. Además, algunas entidades del tercer sector se encuentran en dificultades para competir con empresas capitalistas en la provisión de servicios de cuidados al colectivo analizado, sin que todas se encuentren en una misma disposición para cubrir las necesidades de atención a la dependencia.

\section{Palabras Clave:}

Ley de la Dependencia, tercer sector, servicios sociales, Estado del bienestar, políticas de austeridad. 


\section{Introducción}

Han transcurrido diez años desde que se aprobó la Ley 39/2006, de Promoción de la Autonomía Personal y Atención a las Personas en Situación de Dependencia (en adelante, Ley de la Dependencia) y el 1 de julio de 2015 venció el plazo para la incorporación al sistema de los calificados con grado I. Una ley destinada a hacer frente a uno de los denominados nuevos riesgos sociales (new social risks): los cuidados. En ella se reconoce un derecho subjetivo de ciudadanía a las personas en situación de dependencia y se establece un sistema que ofrece diferentes alternativas para la provisión de cuidados a este amplio colectivo. Su justificación viene dada por un cúmulo de factores causales: una dinámica demográfica caracterizada por el envejecimiento de la población y el aumento de la esperanza de vida, cambios en las estructuras familiares, la emergencia de nuevos valores sociales, la creciente incorporación de la mujer al mercado laboral y cambios en su rol económico, lo que trastoca las prácticas familiares de atención a la dependencia. Esta conjunción de factores alentaban la configuración de un sistema que diese respuesta a la crisis de los cuidados, y que se abordó con la citada Ley.

Ante este reto, la Ley de la Dependencia configuró un sistema en el que sobresale un catálogo de herramientas que trata de dar respuesta a los objetivos marcados en aquélla, y que se divide en dos grandes bloques: por un lado, los servicios; y por otro, las prestaciones económicas. Con todo, tras estos diez años, no parece que la Ley esté aplicándose plenamente ni cumpliendo sus principios clave (carácter público de las prestaciones, universalidad e igualdad, atención integral e integrada), con signos de disparidades territoriales. A lo dicho hay que unirle su práctica concurrencia temporal con una crisis económica que alcanza hasta la actualidad, lo cual complica su ejecución.

El objetivo planteado en este texto es efectuar un balance de la situación en el ámbito de la cobertura de las necesidades de las personas en situación de dependencia, y obtener una valoración sobre el estado y el grado de cumplimento de la Ley en el territorio valenciano.

Marcado el propósito, se partió de la hipótesis de que el desarrollo del sistema en el País Valenciano no ha respondido a las exigencias fijadas en la Ley, dejando en una clara posición de desventaja a las personas dependientes. Todo ello coadyuvado por un elevado grado de incumplimiento de la legalidad por parte de las autoridades políticas valencianas, lo que entorpece o dificulta la consecución de una atención adecuada al colectivo objeto de estudio. Esta situación ya la recogía Carmen Montalbá para el período 2006-2012 en varios textos (2013a, 2013b), en los que subrayaba la "nula cultura de la legalidad" existente en la autonomía valenciana. Aneja a esta hipótesis, existe la sospecha de que son las asociaciones del tercer sector quienes están supliendo parte de las actuaciones que atañen a las Administraciones públicas.

El texto está estructurado en tres apartados, además de esta introducción. El primero esboza el marco general significativo para comprender cómo se concreta la prestación de servicios que cubre las necesidades de las personas dependientes. A continuación, en un segundo apartado, se fija la atención en los mecanismos de cobertura de los cuidados en el País Valenciano, con especial referencia al área metropolitana de València. Termina el texto con las conclusiones finales.

Para dar respuesta a los objetivos y comprobar las hipótesis, se recurrió a la revisión de la literatura especializada, así como al empleo de la técnica de la entrevista en profundidad, de tipo semiestructurada. En ésta, se partió de un guion previo, cuyo fin era canalizar las respuestas de los entrevistados, aunque sin pretender efectuar entrevistas directivas, pues uno de los intereses era recabar "la información particular de cada entrevistado, además de captar aspectos no previstos en el guion" (Vallés, 1999: 204) y lograr una dinámica fluida en la relación comunicativa. Para la elección de las personas entrevistadas, se optó por contactar con actores clave del sector de la dependencia, especialmente trabajadores sociales de servicios públicos municipales y de entidades del tercer sector que operan con el grupo estudiado, y agentes sociales implicados, todos ellos con un profundo conocimiento sobre la cuestión. Existía la alternativa de recurrir a los protagonistas directos de las actividades de atención a la dependencia vinculados al sistema definido por la Ley (las personas beneficiarias, sus familias, las distintas categorías de trabajadores vinculados a la prestación de servicios). Sin embargo, optamos por el recurso a aquellos actores que disponen de una visión integral del sistema y de su proceso de conformación. Desgraciadamente, entre estos últimos no fue posible contar con la participación de representantes de la Administración pública regional, que justificó su rechazo a participar por la carga de trabajo que suponía la celebración de los comicios autonómicos y locales. Las entrevistas fueron grabadas en audio para su posterior transcripción, garantizándose al informante el anonimato y la confidencialidad. Fueron once las entrevistadas realizadas (Cuadro 1), todas ellas en el período comprendido entre abril y julio de 2015. El ámbito territorial en el que se realizó el trabajo de campo fue el área metropolitana de València. 


\begin{tabular}{|c|c|c|}
\hline \multicolumn{3}{|c|}{ Cuadro 1. Informantes clave } \\
\hline $\begin{array}{l}\text { № } \\
\text { entrevista }\end{array}$ & Perfil del entrevistado & $\begin{array}{l}\text { Duración } \\
\text { entrevista }\end{array}$ \\
\hline$E_{1}$ & $\begin{array}{l}\text { Representante de UGT-Pais Valencià y } \\
\text { miembro de la Plataforma en Defensa } \\
\text { de la Llei de la Dependència }\end{array}$ & $1 \mathrm{~h} 40 \mathrm{~m}$ \\
\hline$E_{2}$ & $\begin{array}{l}\text { Trabajadora social de CC.OO.-Pais } \\
\text { Valencià y miembro de la Plataforma en } \\
\text { Defensa de la Llei de la Dependència } \\
\end{array}$ & $1 \mathrm{~h} 20 \mathrm{~m}$ \\
\hline $\mathrm{E}_{3}$ & $\begin{array}{l}\text { Trabajadora social en la Asociación } \\
\text { Valenciana de Dependientes y } \\
\text { Cuidadores }\end{array}$ & $1 \mathrm{~h} 20 \mathrm{~m}$ \\
\hline $\mathrm{E}_{4}$ & $\begin{array}{l}\text { Trabajadora Social y responsable en la } \\
\text { Asamblea Local de València de la Cruz } \\
\text { Roja* }\end{array}$ & $1 \mathrm{~h} 4 \mathrm{om}$ \\
\hline $\mathrm{E}_{5}$ & $\begin{array}{l}\text { Trabajador social y responsable de la } \\
\text { Asociación de Daño Cerebral Adquirido } \\
\text { de València** }^{\star \star}\end{array}$ & $1 \mathrm{~h} 35 \mathrm{~m}$ \\
\hline$E_{6}$ & $\begin{array}{l}\text { Terapeuta ocupacional y corresponsable } \\
\text { de la Asociación de Daño Cerebral } \\
\text { Adquirido }\end{array}$ & $1 \mathrm{~h} 25 \mathrm{~m}$ \\
\hline $\mathrm{E}_{7}$ & 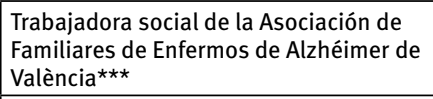 & $1 \mathrm{~h} 10 \mathrm{~m}$ \\
\hline $\mathrm{E}_{8}$ & $\begin{array}{l}\text { Trabajadora social de servicios sociales } \\
\text { municipales del área metropolitana de } \\
\text { València y profesora de la Universitat } \\
\text { de València }\end{array}$ & $1 \mathrm{~h} 35 \mathrm{~m}$ \\
\hline $\mathrm{E}_{9}$ & $\begin{array}{l}\text { Trabajadora social de los servicios } \\
\text { sociales municipales del área } \\
\text { metropolitana de València }\end{array}$ & $1 \mathrm{~h} 20 \mathrm{~m}$ \\
\hline$E_{10}$ & $\begin{array}{l}\text { Representante de una orden religiosa } \\
\text { sita en la ciudad de València, con } \\
\text { labores de formación e intermediación } \\
\text { laboral }\end{array}$ & $1 \mathrm{~h} 05 \mathrm{~m}$ \\
\hline$E_{11}$ & $\begin{array}{l}\text { Trabajadora social de un centro de salud } \\
\text { municipal del área metropolitana de } \\
\text { València }\end{array}$ & $1 \mathrm{~h}$ \\
\hline
\end{tabular}

* Cruz Roja Comunitat Valenciana forma parte de la Plataforma del Tercer Sector Social de la Comunitat Valenciana.

** Asociación miembro, entre otros, de la Federación Española de Daño Cerebral (FEDACE), de la Federación Valenciana de Daño Cerebral (FEVADACE), de la Federació de Persones amb Discapacitat Física i Orgánica de la Provincia de València (COCEMFE) o de la Plataforma de Voluntariat de la Comunitat Valenciana (PVCV).

*** Asociación que pertenece a la Federació Valenciana d'Associacions de Familiars de Persones amb Alzheimer (FEVAFA). Al mismo tiempo, FEVAFA participa en la Xarxa de Xarxes d'Acció Social i Cooperació al Desenvolupament.

Fuente: Elaboración propia.

\section{Marco general. Factores significativos en la cobertura de las necesidades de las personas dependientes en la actualidad}

En este epígrafe, y actuando como marco conceptual sobre el que construir el análisis del caso objeto de estudio, se abordarán:

- Los diferentes ámbitos de provisión y prestación de cuidados.

- Los diferentes modelos de Estado del bienestar, haciendo hincapié en los países incardinados en la denominada vía mediterránea, caracterizada por su familiarismo, aunque sin dejar de lado el influjo de la ideología neoliberal desde finales de los años setenta del siglo pasado.
- Una mirada a la Ley de la Dependencia y a las posibilidades que ofrece para satisfacer las necesidades del colectivo en función del esquema anterior de provisión de cuidados.

- El gobierno multinivel y la necesaria cooperación entre los niveles de gobierno, dado que la Ley la aprueba la Administración central, pero hay una descentralización competencial a favor de las comunidades autónomas, y, a la par, las corporaciones locales son los entes que se enfrentan diariamente a los problemas de la ciudadanía, y en el caso que aquí nos ocupa, a las vicisitudes del grupo analizado.

- Las consecuencias de la crisis económica, etapa bautizada como ‘Gran Recesión', y las respuestas políticas que se le han dado, con dos etapas diferenciadas: una fase de políticas expansivas, de 2008 hasta mayo de 2010; y otra, desde esta última fecha hasta la actualidad, con políticas de signo contrario, de austeridad y contención del gasto, que se han traducido en recortes y retrasos en los pagos por parte de la Administración.

\subsection{Esquema de posibilidades en la cobertura de los cuidados}

En el Estado español, antes de la aprobación de la Ley de la Dependencia las personas en situación de dependencia se veían protegidas por la acción de los servicios sociales, una vez incorporados como pilar del Estado del bienestar a partir de la instauración y consolidación de la democracia. En efecto, el despliegue de un sistema público de servicios sociales se vio entorpecido por un largo régimen dictatorial en el Estado español (Sancho Castiello, 2006). No obstante, y pese al impulso de esta vertiente del Estado del bienestar en las décadas de los ochenta y noventa, la provisión de cuidados no ha sido cubierta plenamente por el Estado, sino que el creciente protagonismo del sector público se ha visto acompañado de un proceso paulatino de mercantilización en las tareas de cuidados. Este proceso se situó en paralelo con el desarrollo de los servicios prestados por las mismas entidades locales y el tercer sector, sin dejar en el olvido que la atención en el núcleo familiar seguía (y sigue) siendo el principal elemento de provisión de cuidados, con peculiaridades regionales (Martínez Buján, 2014).

De esta manera, puede establecerse un andamiaje institucional de provisión y prestación de cuidados articulados sobre la familia, el mercado y el Estado. Otros autores incluyen como vértice adicional a las organizaciones sin ánimo de lucro. Esto último conduce a la denominada organización social del cuidado (social care) [Daly y Lewis, 2000: 286; Rodríguez Enríquez, 2015: 40], o el conocido como 'diamante de cuidados' (Razavi, 2007: 21). Ambas formas se representan en la Figura 1. 

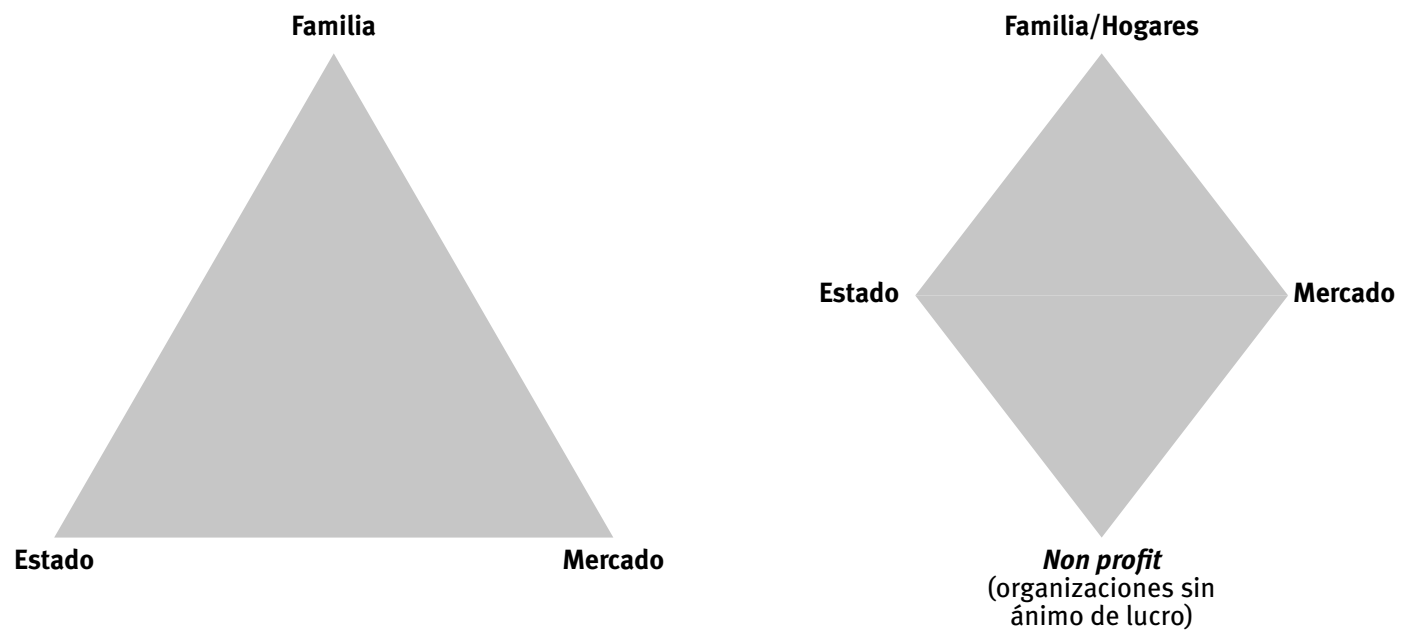

Fuente: Razavi (2007: 21), para el ‘diamante de cuidados’, y elaboración propia.

Con la intención de engarzar los tipos de provisión dentro de las diferentes clasificaciones de regímenes del Estado del bienestar, emergió el concepto de regime care, en el que el género se constituye como vector en torno al cual giran las políticas del bienestar y la articulación del Estado, el mercado y la familia (Torns, 2014: 16). Asimismo, merece la pena ampliar la muestra e introducir los regímenes de cuidado familiar o family care regimes (Pfau-Effinger, 2014; Flaquer, Pfau-Effinger y Artiaga, 2014), clasificación que incluye tres tipos de cuidados (formal, informal y semiformal) y en la que figuran tres ejes clave, como son el ámbito en el que se desarrolla el cuidado (doméstico/ extraodoméstico), el tipo de trabajo efectuado (reproductivo/mercantil) y el marco regulatorio (sujeto o no a un marco jurídico) [Muñoz, 2015].

Pese a todo, las distintas esferas de prestación de cuidados son complementarias y, en ocasiones, sus campos de actuación se ven solapados. Así, es perfectamente compatible el cuidado de la persona en situación de dependencia en el ámbito doméstico por la familia con algún servicio complementario, bien sea concedido por la Administración pública, bien ofrecido por el mercado. Además, hay situaciones que quedan en un ámbito intermedio entre las diferentes esferas. Es el caso, por ejemplo, de la provisión de los servicios ofertados por la Ley de la Dependencia llevada a término por empresas y organizaciones que actúan en el ámbito mercantil, pero a través de conciertos o convenios con las autoridades públicas (locales o autonómicas). Otra situación a medio camino entre los espacios prestatarios es el de la 'migrante en la familia' (Bettio, Simmonazi y Villa, 2006: 272; León, 2010; García Sainz, 2011; Da Roit y Weicht, 2013; Van Hooren, 2014; Muñoz y Pitxer, 2016). En este último supuesto, cabe la posibilidad de que la Administración conceda una prestación económica para el cuidado en el entorno familiar y, con esta cuantía, se decida contratar a una persona, mayoritariamente mujer inmigrante, para cubrir la necesidad de cuidados.

\subsection{Modelos de bienestar existentes}

Las estrategias para prestar la atención oportuna a las personas dependientes vienen marcadas por los diferentes regímenes del Estado del bienestar, que, a su vez, se configuran en función del predominio o peso de cada uno de los ámbitos prestatarios presentados en el epígrafe anterior. Se parte de la base de la existencia de cuatro regímenes del bienestar diferenciados: a) un modelo anglosajón liberal, con un papel residual del Estado; b) un modelo nórdico socialdemócrata, de carácter universalista y con un elevado grado de intervención de los poderes públicos; c) otro continental corporativista, propio de los países centroeuropeos, en el que la protección social va aneja a la condición de trabajador o no; y por último, d) el propio de los países del sur de Europa (Moreno et al., 2014: 13-14). Para el caso aquí analizado, nos centramos en el régimen de los países de la vía media o mediterránea, que destaca por su carácter familiarista, al ser el núcleo familiar la institución que principalmente proporciona el cuidado necesario a las personas en situación de dependencia, al tiempo que dispone de una débil oferta pública de servicios sociales que sirve de apoyo (Moreno Fuentes, 2015: 57). Debe subrayarse que hay una interdependencia mutua entre ambas características 
del modelo ya que, al no existir una red de servicios sociales públicos suficientemente desarrollada, es el núcleo familiar quien debe hacer frente a estas carencias (Naldini y Guerrero, 2009). A su vez, este perfil concreto de la vía mediterránea no es ajeno a la influencia decisiva de aspectos de cariz cultural, histórico o familiar (Castles y Miller, 1993; Guillén y León, 2011; Daatland, 2015: 33-34).

Ahora bien, la referencia a la familia como protagonista principal en la prestación de cuidados no ofrece una imagen completa de la realidad, en tanto que oculta un aspecto crucial: quién asume el grueso de la carga de cuidados. A este respecto, no podemos pasar por alto que es la mujer en el seno del hogar quien se encarga de proveer estos cuidados, entre otros, a las personas mayores o personas en situación de dependencia. Tradicionalmente, la mujer ha venido desempeñando este papel de dispensar bienes y servicios en el hogar dentro del marco del trabajo reproductivo. No obstante, de manera paulatina se ha avanzado en la mercantilización de las tareas del hogar y del cuidado, en especial, a partir de la incorporación más sólida de un número creciente de mujeres al mercado laboral. Además, a medida que se ha producido un aumento de la mujer foránea en el continente europeo, ésta ha sido empleada en algunos nichos laborales, como el servicio doméstico y las tareas del cuidado, subrayándose así la ilación entre la variable migratoria femenina y los cuidados (Colectivo loé y Fernández, 2010; Martínez Buján 2011, 2014).

En suma, el Estado del bienestar español se incardina en la vía mediterránea y se caracteriza por conjugar rasgos del modelo corporatista (caso de las pensiones), del modelo nórdico (educación y sanidad) y del anglosajón (la debilidad o escaso desarrollo de los servicios sociales). Se le unen aspectos tales como la distribución de la cobertura entre la familia y otros actores institucionales, una gestión pública descentralizada o la competencia entre el sector mercantil y el no lucrativo por participar en la externalización de servicios públicos (Rodríguez Cabrero, 2011b: 34).

Asimismo, la conformación del Estado del bienestar español, como sostiene Rodríguez Cabrero (2011a: 20-25), muestra unas fases claramente diferenciadas: una fase de expansión (1975-1985), otra de consolidación (1986-1995), a la que le sigue la de europeización (1996-2005), y concluye con la calificada como de recalibración (de 2006 en adelante). Es en la fase de europeización cuando tienen lugar avances significativos en materia de derechos civiles y sociales, especialmente en el final de ésta, con Gobiernos del Partido Socialista. Se aprueban leyes como la relativa a la protección contra la violencia de género, la de igualdad efectiva entre hombres y mujeres, o la Ley de la Dependencia (León y Pavolini, 2014: 359). Los efectos más negativos acontecerán a partir de la crisis de $\mathbf{2 0 0 8 ,}$ ciclo en el que, como consecuencia de las políticas de austeridad, "se ha abortado una importante iniciativa pública de apuntalamiento de la transformación socio-cultural de la imagen de la mujer, de su rol en los servicios de cuidado personal y de su inserción en el mercado de trabajo" (Guillén, González-Begega y Luque, 2015: 10).

A la vista de estas fases, en la conformación del Estado del bienestar español hay que resaltar el desajuste temporal de treinta años respecto al desarrollo de dicho Estado del bienestar en otros países (o bloques) del Viejo Continente. Por lo que respecta a la Europa Occidental, hay tres etapas (Moreno et al., 2014: 16-22; Moreno, 2015). La primera se denomina "treinta años gloriosos" o Edad de Oro (1945-1975), con pleno empleo (masculino) y una alta actividad de las autoridades públicas en pro de la protección social de los más desfavorecidos cuando no eran atendidos en la familia o el mercado. Esta Edad de Oro se ve truncada por la crisis de los años setenta y el cuestionamiento de la actuación pública. Comienza, pues, un proceso de debilitamiento en cuanto al protagonismo del Estado, coincidiendo con la ofensiva de la ideología neoliberal. El objetivo ahora es abandonar la labor garantista que hasta ese momento habían desempeñado los poderes públicos para suplirla por las fuerzas del mercado. Es la fase que recibe el nombre de Edad de Plata del Estado del bienestar (1976-2007) y en la que se impela hacia la reducción o contracción de éste (retrenchment), o se favorece su 'residualización' (Sainsbury, 1996: 198). Pese a todo, la contracción no ha sido homogénea. Mientras que en los países continentales y escandinavos se vio reordenada la intervención pública y el gasto en política social, los países del sur de Europa tendieron a incrementar porcentualmente su gasto en este campo de actuación (Guillén, González-Begega y Luque, 2015: 2, Equipo NorSpan, 2015: 23), con una tendencia hacia la convergencia en gasto social. Hoy día ya se habla de una Edad de Bronce (a partir de 2008), iniciada con la Gran Recesión y que se extiende hasta nuestros días, con la pregunta en el aire acerca del futuro del Estado social en Europa. Además, el grupo de países que conforman la vía mediterránea se ha visto obligado a implantar reformas tendentes a la reducción del gasto público (y de modo particular, del gasto social), a limitar los servicios prestados y a trasladar la cobertura de los nuevos riesgos sociales a las esferas mercantil y familiar (Guillén, González-Begega y Luque, 2015: 3), sin olvidar la contribución del tercer sector. Todos estos cambios conducen a lo que se ha dado en llamar recalibración o restructuración del Estado del bienestar (Rodríguez Cabrero, 2011b), al socaire de los principios de corte neoliberal provenientes de la Unión Europea y agravada por el azote de la crisis económica actual $^{2}$. Esas presiones desde instancias supranacionales han supuesto la reconfiguración

${ }^{2}$ La Unión Europea ha marcado la senda de actuación en materia de políticas sociales y del Estado del bienestar. Por un lado, con el contenido fijado en la Estrategia de Lisboa 2000 y con la Estrategia Europea 2020. Y por otro, con las indicaciones a los Estados miembros, especialmente a los países no centrales, de establecer como marco esencial las políticas de austeridad y reducción del gasto público (Foessa, 2014: 315). 
del Estado del bienestar por diferentes vías y con resultados diversos, fragmentando la homogeneidad de los países del sur de Europa, proceso éste que ha alcanzado de pleno al Estado español.

\subsection{La Ley de la Dependencia. Un breve análisis sobre el modelo de provisión}

La Ley de la Dependencia, fruto de la concertación social entre los actores sociales y el Gobierno, es "el resultado de una senda acumulativa de factores socioeconómicos e institucionales y de la participación de distintos actores sociales" (Marbán, 2011: 377). Representa un intento de superar el tradicional esquema de provisión, con la familia como principal sostén y la mujer en primera línea (Fantova, 2015: 54). Esta ley oferta un catálogo de servicios y prestaciones económicas (Cuadro 2) del que pueden beneficiarse aquellas personas que hayan sido reconocidas en situación de dependencia por las autoridades competentes.

\begin{tabular}{|c|c|}
\hline \multicolumn{2}{|c|}{$\begin{array}{l}\text { Cuadro 2. Catálogo de servicios y prestaciones } \\
\text { económicas contenidos en la Ley de la Dependencia }\end{array}$} \\
\hline Prestaciones & Tipos \\
\hline \multirow{5}{*}{ Servicios } & $\begin{array}{l}\text { Servicio de prevención de situaciones de } \\
\text { dependencia y promoción de la autonomía } \\
\text { personal }\end{array}$ \\
\hline & Servicio de teleasistencia \\
\hline & Servicio de ayuda a domicilio \\
\hline & Servicios de centros de día y de noche \\
\hline & Servicios de atención residencial \\
\hline \multirow{3}{*}{$\begin{array}{l}\text { Prestaciones } \\
\text { económicas }\end{array}$} & Prestación económica vinculada al servicio \\
\hline & $\begin{array}{l}\text { Prestación económica para cuidados en el } \\
\text { entorno familiar y apoyo a cuidadores no } \\
\text { profesionales }\end{array}$ \\
\hline & Prestación económica de asistencia personal \\
\hline
\end{tabular}

Fuente: Elaboración propia

Sin embargo, pese al catálogo común de servicios y prestaciones, y a definir unos principios de actuación, hay disparidades autonómicas. El despliegue del Estado del bienestar no puede, en este sentido, desligarse del proceso descentralizador de los ochenta y noventa a favor de las comunidades autónomas, ni de la consiguiente falta de homogeneidad en el territorio español (Gallego, Gomà y Subirats, 2005: 104; Gallego y Subirats, 2011: 100; Del Pino, 2013; León, Ranci y Rostgaard, 2014: 14). Estas diferencias, incluso, van más allá del plano autonómico, al observarse contrastes dentro de cada región en función del enclave -urbano, semiurbano o rural-, lo que apunta la relevancia de la dimensión territorial. De ahí la importancia de concretar en el trabajo de campo la comunidad autónoma y el territorio objeto de estudio.

Pese a estas diferencias territoriales, es importante resaltar qué propone la Ley. Ésta reconoce la necesidad de dar respuesta, desde los poderes públicos, a las necesidades del colectivo, y se reafirma en su propósito de promocionar y dotar de recursos al sistema con un grado significativo de provisión pública en la cobertura de las necesidades de las personas dependientes. Sin embargo, dentro de los principios inspiradores recogidos en la Ley, se abre la puerta a la vía mercantil, a través de empresas con ánimo de lucro o de organizaciones del tercer sector. Es más, como finalidad del Sistema para la Autonomía y Atención a la Dependencia (SAAD) se fija que éste quedará configurado como una red de uso público formada por centros y servicios públicos y privados. Reconoce, pues, que los servicios del catálogo se prestarán a través de la red de servicios sociales, si bien dicha red la conforman tanto centros de titularidad pública como centros privados debidamente autorizados. Por tanto, la pregunta que debe formularse es si existen suficientes centros de titularidad pública o si, en su defecto, hay una voluntad real de promover su creación. Y ni una cosa ni la otra son ciertas, pues se desvía al sector mercantil la prestación de estos servicios, sea a través de convenios o de conciertos.

Por otro lado, no hay que descuidar a las prestaciones económicas, cauce por el que el Estado acaba delegando en las familias la responsabilidad y las decisiones sobre el cuidado. Esta opción tiene su base en el asentamiento de un ideario más individualista y consumista, favorable a la libre elección del cuidado (Ungerson, 1999; Ranci y Pavolini, 2015: 11). Así, la concesión de una cuantía económica a la persona en situación de dependencia promueve que sea ésta (o, en la mayoría de ocasiones, su familia) quien decida finalmente el modo por el que se le provee la atención que estime conveniente. De entre las prestaciones, destacaremos las dos más empleadas. Una es la prestación económica vinculada al servicio, sea residencial, de centro de día, o de un servicio de ayuda a domicilio. Otra es la prestación económica por cuidados en el entorno familiar, en la que caben dos opciones: o bien esa prestación compensa a algún miembro de la familia para que se dedique al cuidado de la persona dependiente, o bien se opta por la mercantilización del cuidado en el seno doméstico, destinando esa prestación a contratar los servicios de personal, mayoritariamente mujer inmigrante y dentro de los márgenes de la economía informal. El recurso a estas prestaciones económicas, pese a la excepcionalidad que formalmente les confiere la Ley, es lo habitual: cerca del $50 \%$ del gasto total en atención a la dependencia se destina a estas prestaciones de carácter económico.

\subsection{La coordinación entre los diferentes niveles de gobierno (gobierno multinivel) y con otros actores}

La Ley de la Dependencia es una ley estatal que fija las condiciones básicas para la atención a la dependencia. Su aplicación, en cambio, corresponde a las comunidades autónomas, al tener transferidas competencias en esta materia, y en este sentido, 
todos los estatutos de autonomía recogen los servicios sociales como competencia propia. A su vez, y a pesar del carácter recentralizador de la última reforma local, las corporaciones locales son las autoridades públicas de proximidad para el ciudadano, autoridades que se enfrentan, en su quehacer diario, con los problemas que aquejan a su población, en nuestro caso, los solicitantes de atención a la dependencia. De este modo, hay tres niveles de gobierno implicados en la atención a la dependencia: el estatal, el autonómico y el local.

Observando el articulado, la Ley apunta hacia una cooperación interadministrativa de todos los niveles de gobierno, siendo incluso iterativa su presencia en el texto y creándose un órgano exclusivo para esta función cooperativa: el Consejo Interterritorial, rebautizado en 2012 como Consejo Territorial de Servicios Sociales y del SAAD.

De entre las principales competencias del nivel autonómico, destaca la planificación, ordenación, coordinación y dirección de los servicios del catálogo. Por otro lado, las entidades locales también figuran en el texto legal, que recoge su participación en la gestión de los servicios de atención, sobre la base de la normativa autonómica, aunque sin el mismo protagonismo que las comunidades autónomas.

Se recogen así los tres niveles de gobierno, instándose a la cooperación entre ellos. Pero además, la Ley añade la participación de la iniciativa privada y del tercer sector, al tiempo que crea órganos de consulta y asesoría, como el Comité Consultivo. Este último es un órgano asesor que garantiza la participación social e institucional, incluyendo los distintos niveles de gobierno, junto con representantes de organizaciones sindicales y empresariales, y de algunos colectivos de afectados.

Visto el marco establecido, se requieren dosis elevadas de coordinación para cubrir satisfactoriamente los servicios de atención a la dependencia, como bien anotan Barbieri y Gallego (2015: 94) o Rodríguez Cabrero (2016: 36). Y en este entramado de responsabilidades compartidas, se debe prestar un protagonismo destacado al nivel local, ámbito privilegiado de conexión entre las necesidades y la oferta de servicios.

Desafortunadamente, ni la coordinación ni la descentralización son facetas que se hayan resuelto satisfactoriamente hasta el momento. Incluso se ha experimentado una involución, fruto de la incertidumbre generada por la Ley de Racionalización y Sostenibilidad de la Administración Local (27/2013), que deja sin resolver completamente sobre quién debe recaer la competencia en materia de servicios sociales. Al respecto, la Asociación Estatal de Directoras y Gerentes de Servicios Sociales (2015a) somete a dura crítica la Ley, tanto por los recortes sociales que subyacen en ella como por la renuncia a la proximidad en la prestación del servicio:
[...] la Ley responde impidiendo que los municipios puedan ejercer las competencias que le resultan incómodas al Gobierno en manos de lo local por no coincidir con su modelo de Estado del bienestar (sanidad, educación y, sobre todo, servicios sociales), por el expeditivo método de declararlas unilateralmente 'impropias'; pero, eso sí, reservándose la posibilidad de delegárselas cuando convenga (no cuando les convenga a los municipios, que no tienen derecho a decidir autónomamente, sino a las comunidades autónomas), con la alevosía, por añadidura, de 'dictar' en qué condiciones, con qué límites y características haya de prestar los servicios, concretamente los servicios sociales, el municipio en cuestión.

\subsection{La Gran Recesión}

El Estado español había vivido una etapa de crecimiento económico sobresaliente desde 1994 hasta 2007, pero sobre la base de un modelo frágil (Banyuls, 2014). Un modelo productivo en el que la construcción era la locomotora de la economía, y arrastraba a otros sectores de la industria y los servicios. Un modelo intensivo en mano de obra, pero con baja productividad y poco valor añadido, que permitió crear puestos de trabajo rápidamente, aunque sobre cimientos poco sólidos.

A esta etapa le sigue un período de crisis, cuya incidencia es especialmente intensa a causa de las mencionadas debilidades de nuestro modelo productivo. Desde el inicio de la crisis, las consecuencias han sido dramáticas en muchos ámbitos: aumento del desempleo, de los parados de larga duración, de las familias sin ninguna persona activa ocupada; crecimiento de los índices de pobreza, desigualdad, marginalidad y de exclusión social. La respuesta de los poderes públicos a estos problemas ha seguido dos etapas claramente diferenciadas. La primera, de 2008 a mayo de 2010 , de corte keynesiano; y la segunda, desde 2010 hasta la actualidad, de austeridad, con fuertes recortes en el gasto público (especialmente las partidas de carácter social) y aumento de la imposición indirecta ${ }^{3}$.

El ámbito de la dependencia no se ha mantenido ajeno ni a la intensificación de los problemas en el período de crisis, ni a la oleada de reformas y recortes presupuestarios citados. En 2010 y 2011, el Gobierno socialista introdujo novedades de signo restrictivo, pero el punto de inflexión más significativo tuvo lugar con el Partido Popular en el poder, que endureció las condiciones. Se suspendió la incorporación de las personas valoradas con el grado I hasta el

${ }^{3}$ En esta última etapa, también puede haber un deslinde, concretamente en 2012, con el endurecimiento de las políticas de austeridad, y sobre todo, las reformas emprendidas por el Partido Popular. A su vez, no podemos olvidar la relajación en estas cuestiones inherente a las últimas convocatorias electorales. 
1 de julio de 2015, se simplificó la baremación (se mantuvieron los grados y desaparecieron los niveles), y se redujeron las cuantías de las prestaciones que perciben las personas dependientes y la intensidad de los servicios. Por último, se alteraron los convenios especiales de los cuidadores no profesionales (los cuidadores familiares) con la Seguridad Social, pasando de ser financiados por el Estado a tener un carácter voluntario para el cuidador, que es quien asume el abono (Del Pino, 2013; Tortosa, 2016). A todo esto se le añade el aplazamiento en los pagos de las deudas por parte de las Administraciones públicas.

\subsection{Un protagonismo creciente del tercer sector}

Hay muchas vaguedades sobre la definición del tercer sector. Acreditados expertos sobre esta materia recogen el término 'economía social' y señalan "ambigüedades" a la hora de dotarlo de contenido (Monzón, 2006). Así y todo, de lo que no cabe duda es de que hay ocasiones en las que ni el Estado ni el mercado son capaces de dar respuesta a las necesidades y demandas de la sociedad, $y$, en consecuencia, se buscan alternativas para satisfacerlas. Es ahí donde adquiere protagonismo el tercer sector, con reconocidas funciones de utilidad económica, entre las que consta la oferta de servicios de bienestar social (Chaves y Monzón, 2003: 16).

Dentro del tercer sector, se agrupan organizaciones diversas. Por regla general, se clasifican a partir del colectivo destinatario o bien en función de las actividades que desarrollan, como sucede con las organizaciones categorizadas como tercer sector de acción social. En la materia aquí tratada, es acertado sacar a relucir la oferta de servicios de bienestar social dirigidos a colectivos como las personas mayores o las personas con diversidad funcional. No obstante, éste es un campo de actuación en el que el tercer sector ha participado muy activamente desde mucho tiempo antes de la aprobación de la Ley de la Dependencia (Marbán, 2008).

En cualquier caso, y para superar las ambigüedades terminológicas, puede asumirse la definición contenida en la Ley del Tercer Sector de Acción Social, que lo define como:

Aquellas organizaciones de carácter privado surgidas de la iniciativa ciudadana o social, bajo diferentes modalidades, que responden a criterios de solidaridad y de participación social, con fines de interés general y ausencia de ánimo de lucro, que impulsan el reconocimiento y el ejercicio de los derechos civiles, así como de los derechos económicos, sociales o culturales de las personas y grupos que sufren condiciones de vulnerabilidad o que se encuentran en riesgo de exclusión social (art. 2).

Con la intención de arrojar luz al respecto, y siguiendo el VII Informe Foessa (2014), puede identificarse una secuencia temporal desde la génesis hasta la actualidad en torno al tercer sector de acción social, con tres etapas diferenciadas: una primera (1978-1992), de eclosión del sector; una segunda (1993-2007), coincidente con la etapa de bonanza en el Estado español y en la que destaca su crecimiento, su profesionalización y su consolidación; y una tercera (de 2008 en adelante), de "recalibración" (ibídem: 375).

Debe destacarse que un buen número de asociaciones y fundaciones cumplen con los requisitos exigidos en la Ley: casi 30.000 entidades, según el Anuario del Tercer Sector de Acción Social en España 2012. Una parte importante de ellas tiene como grupo de trabajo las personas en situación de dependencia: en 2015, 12,8\% declaran trabajar con este colectivo; un $7,0 \%$, con personas mayores; y un $37,1 \%$, con personas con discapacidad (Ruiz Villafranca, 2015: 31).

El resultado es un conjunto de entidades caracterizado, entre otros rasgos, por una fuerte fragmentación derivada de los diferentes niveles de gobierno implicados y de la elevada dependencia económica del sector público, lo que perjudica la autonomía de las organizaciones que lo conforman (Rodríguez Cabrero, 2005: 83-84).

Ahora bien, desde la perspectiva de la prestación de servicios destaca la incidencia de la crisis sobre el tercer sector de acción social. De un lado, han crecido las necesidades a atender, tanto por su aumento como a causa de los recortes en gastos sociales; $y$ de otro, se ha reducido la financiación que reciben estas entidades a partir de 2010 (Ruiz Villafranca, 2015). Estas organizaciones han tenido que dedicar cada vez más esfuerzo a proveer servicios de atención que correspondían a la Administración, y al mismo tiempo, han debido competir con el sector mercantil (Homs, 2009: 18). Ante esta situación, algunas entidades han optado por adaptarse a los nuevos tiempos y avanzar hacia una gestión más profesionalizada, mientras que otras han seguido una línea más amateur, estando estas últimas en peor disposición para afrontar los desafíos que acarrea el contexto actual. Por tanto, el tercer sector también se ha visto afectado por la crisis económica iniciada en 2008, como destacan diversos trabajos (Foessa, 2014; Homs, 2009; Ruiz Villafranca, 2015; Marbán, 2016). Homs (2009: 22-26) señala cinco efectos directos de la crisis, a saber: a) el aumento de las necesidades sociales; b) una menor dotación presupuestaria a las entidades del tercer sector por parte de las Administraciones públicas; c) el descenso de la actividad económica en general (y consecuentemente, de la demanda de productos y servicios, que afecta, a su vez, al mercado de trabajo); d) una oferta del crédito financiero limitada; y e) la reducción de otras fuentes de ingresos, como pueden ser las aportaciones de los miembros de estas entidades. Ante este panorama, la respuesta ha consistido en un aumento considerable del número de atenciones directas, a pesar de la reducción tanto de los recursos económicos como del empleo en las entidades del sector (Ruiz Villafranca, 2015). 


\section{Los mecanismos de cobertura de los cuidados en el País Valenciano}

En este tercer epígrafe, se presentan los principales resultados del trabajo de campo. Aunque el estudio de caso se ha centrado en el área metropolitana de València, consideramos que sus resultados tienen un interés más general, dado que podrían servir para establecer una comparativa con otros territorios del Estado español. Previamente, hay que decir que el papel que se le reconoce a la familia en la prestación de servicios de atención a la dependencia en el País Valenciano quedó ya recogido en otro trabajo (Muñoz y Pitxer, 2016). En él se mostró que, de entre las diversas opciones posibles, predomina el cuidado en el ámbito doméstico por parte de los miembros de la familia, y que los factores con mayor incidencia para la elección de una u otra modalidad son de tipo económico y cultural. En cualquier caso, es la mujer quien, por lo general, se hace cargo del trabajo de cuidados en el ámbito doméstico, ya sea bajo la modalidad de trabajo no mercantil (o reproductivo) como de trabajo mercantilizado, en cuyo caso, queda copado, en su mayoría, por población inmigrante. Del mismo modo, debe remarcarse que recientemente ha tenido lugar una cierta (re)nativización de los cuidados en el trabajo doméstico mercantilizado, al entrar de nuevo mano de obra autóctona en este sector del mercado de trabajo como consecuencia de las dificultades económicas y laborales de los últimos años.

Ahora bien, junto con estos ámbitos de prestación de servicios de atención a la dependencia, también tiene lugar la participación de los servicios sociales, y de empresas y entidades no públicas (mercantiles, en unos casos, y del tercer sector, en otros). Todos ellos afectados tanto por la Ley de la Dependencia como por las respuestas de los poderes públicos a la última crisis.

Efectivamente, aunque el 1 de enero de 2007 entró en vigor la Ley de la Dependencia, ésta ha experimentado diversas modificaciones a partir de mayo de 2010. Así, la política de recortes y reformas iniciada en ese momento ha limitado lo que debía ser un fortalecimiento de la cobertura de cuidados a las personas dependientes con financiación pública. Esta limitación es observable, por ejemplo, en el recurso a las empresas mercantiles o las entidades del tercer sector, en el recurso a la vía de las prestaciones económicas al beneficiario, o en los convenios con las entidades no públicas prestadoras del servicio.

Si bien no disponemos de información completa del catálogo de centros vinculados a los servicios a la dependencia, podemos tomar como ejemplo y referencia a los centros residenciales para personas mayores (Tabla 1), de donde cabe extraer tres ideas generales. La primera, que las plazas existentes no suponen la vía principal de cobertura de las necesidades de atención a las personas mayores, en tanto que éstas representan menos del $5 \%$ del total de personas mayores de 64 años (4,2 \% en España y
2,9\% en el País Valenciano, según Envejecimiento en Red 2015).

Tabla 1. Centros y plazas residenciales. España y País Valenciano, 20154

\begin{tabular}{l|c|c|c|c}
\hline \multirow{2}{*}{} & \multicolumn{2}{|c|}{ Centros } & \multicolumn{2}{c}{ Plazas } \\
\cline { 2 - 5 } España & N & $\%$ & N & $\%$ \\
\hline Privados & 3.803 & 71,2 & 260.566 & 72,6 \\
\hline Públicos & 1.510 & 8,3 & 97.145 & 27,1 \\
\hline Sin datos & 27 & 0,5 & 1.324 & 0,4 \\
\hline Total & 5.340 & 100,0 & 359.035 & 100,0 \\
\hline País Valenciano & 258 & 78,9 & 21.115 & 79,4 \\
\hline Privados & 69 & 21,1 & 5.488 & 20,6 \\
\hline Públicos & 327 & 100,0 & 26.603 & 100,0 \\
\hline Total &
\end{tabular}

Fuente: Envejecimiento en Red (2015) y elaboración propia.

La segunda idea es la escasa presencia del sector público en la oferta del servicio, fenómeno más acusado en el caso valenciano, donde se observa una clara preferencia del decisor público por el sector privado en la prestación de este tipo de servicios. El tercer elemento destacable tiene que ver con la heterogeneidad del conjunto de oferentes no públicos, donde quedan englobadas tanto empresas de corte mercantil como asociaciones y entidades del tercer sector. Sin duda, las empresas con ánimo de lucro serán las protagonistas principales del presente apartado, si bien no podemos perder de vista la importancia creciente del tercer sector.

Hechas estas consideraciones, nos ocuparemos de analizar el papel de los servicios sociales públicos en la atención a la dependencia, y lo completaremos con el del creciente protagonismo de empresas y entidades no públicas en este mismo campo de actividad. Como hemos apuntado más arriba, no abordaremos el papel jugado por la familia en estas funciones, puesto que ya lo hemos hecho en otro momento. En cierto modo, el trabajo actual resulta complementario de ese texto anterior.

\subsection{El papel de los servicios sociales públicos en la garantía de la atención a las personas en situación de dependencia: críticas y sugerencias}

Existen diversos ámbitos prestatarios a los que recurrir para cubrir las necesidades de las personas en situación de dependencia. Uno de ellos es el correspondiente a las Administraciones públicas.

${ }_{4}^{4}$ Centro residencial se refiere a alojamiento colectivo para personas mayores bajo diferentes modelos: residencias (incluidas las minirresidencias), viviendas o pisos tutelados, centros psicogeriátricos (o secciones dentro de esos centros), centros sociosanitarios (o secciones de mayores, si están diferenciadas), conjuntos residenciales (apartamentos o dispositivos similares, con servicios comunes) y otros centros colectivos. 
En este ámbito, un primer aspecto remarcable coordinación adecuada entre los diversos niveles de gobierno implicados. En efecto, dentro de las Administraciones públicas existen dos niveles que tienen potestad para atender a las personas en situación de dependencia: el municipal y el autonómico. El primero gestiona el servicio de asistencia domiciliaria o la teleasistencia, mientras que el segundo administra los servicios del catálogo fijados en la Ley de la Dependencia (Cuadro 2).

En relación con los servicios sociales municipales vinculados con la atención a las personas mayores y dependientes, entre los entrevistados se menciona el servicio de asistencia domiciliaria (en este caso, para el municipio de València), aportando una explicación de su funcionamiento, y haciendo explícita la existencia de duplicidades entre Administraciones, y una carencia de coordinación suficiente entre el nivel local y el autonómico:

En València, existe desde hace muchos años la ayuda domiciliaria, que la presta el Ayuntamiento [...]. Tú tienes que buscar entre las empresas que ellos te dicen cuál es la que se acopla con lo que tú necesitas y el dinero. [...] [El servicio de asistencia domiciliaria] es uno de los recursos que pone la Ley de Dependencia en manos de los usuarios, pero que, como aquí, se aplicó muy mal. Aquí, la Comunidad Valenciana ya tenía una red de los Ayuntamientos, de servicios sociales municipales, pero en vez de utilizar esa red que ya tenía, intentó crear una red de empresas paralelas, a las que acreditó $\left(E_{3}\right)$.

Se aprecia cierto enfrentamiento u oposición entre los profesionales que están en contacto directo con el usuario (a nivel local) y los responsables que deciden desde instancias superiores (a nivel autonómico), lo que muestra deficiencias en materia de coordinación. A tenor de las informaciones de los entrevistados, si bien lo que destaca es la falta de coordinación entre el nivel local y el autonómico, lo cierto es que, como señalan Martínez-Martínez y Uceda-Maza (2015: 106), aparece también un nuevo actor en el entramado, como es la Federación Valenciana de Municipios y Provincias (FVMP), a la que se le encarga la financiación en materia de dependencia a algunos municipios, sobre la base del cumplimiento de unos requisitos concretos ${ }^{5}$ :

[...] es que es descoordinación, es desinformación, es deformación, es que "no pongas eso, tienes que pedirle no sé qué...’, ‘no, perdón, la persona necesita esto'. Y te contestan: 'es que no se lo vamos a dar'. Perdona, ¡la Ley pone que se lo tienes que dar! $\left(\mathrm{E}_{8}\right)$. es la existencia de dificultades y la falta de una

Otro aspecto destacable es optar por un modelo de provisión pública pero con prestación privada, en tanto que no siempre es la propia Administración quien presta el servicio. Con asiduidad, éste se encuentra externalizado, de modo que acaba asumiendo su prestación el sector privado o, en su defecto, el tercer sector. Ello pone de relieve el vaciado de la naturaleza pública de la atención a la dependencia, al menos en cuanto a su prestación:

Tú tienes que buscar entre las empresas que ellos te dicen cuál es la que se acopla con lo que tú necesitas y el dinero. Y siempre tienes tú que poner dinero, y tampoco te va a cubrir sábados y domingos. Sólo de lunes a viernes, y luego los fines de semana, claro, si quieres tú a alguien, va a tener que ser con otra tarifa, que, normalmente, sube bastante de lo de entre semana...; el precio sube... con las mismas empresas $\left(E_{3}\right)$.

Y ya no se trata sólo de optar por la prestación privada, sino que el problema se vio agravado con la introducción del copago ${ }^{6}$, lo que supone que el carácter público de la prestación pasa a ser parcial.

Un tercer rasgo del modelo apunta al reducido protagonismo de los servicios sociales municipales en la prestación de servicios de atención a la dependencia, y ello a pesar de la buena valoración con que cuentan entre las personas necesitadas de esta atención. Efectivamente, en las declaraciones de las personas entrevistadas, los servicios sociales municipales no aparecieron hasta que se formularon las preguntas directamente, desprendiéndose de este silencio que no son tenidos en cuenta a la hora de atender las necesidades del colectivo de la dependencia.

Preguntados sobre el papel de los servicios sociales en relación con la atención que brindan al grupo examinado, hay divergencias según el nivel de gobierno encargado de proporcionar el servicio. Los servicios municipales reciben una valoración positiva de todas las personas entrevistadas, especialmente en función de los escasos recursos con los que cuentan.

En cuanto a los servicios sociales, hay que diferenciar los servicios sociales municipales y los servicios sociales autonómicos... Los servicios sociales [municipales], con los recursos que tenemos, son maravillosos... ( $\left.E_{1}\right)$.

Por el contrario, los juicios negativos predominan cuando se solicita valorar el servicio de atención a la dependencia bajo competencia autonómica. La aplicación de la Ley de la Dependencia en el País Valenciano - de competencia autonómicaes criticada, entre otras cosas, por el carácter

${ }^{5}$ Como ejemplo, que no es el único, sirva la siguiente convocato ria de ayudas publicada en el Diari Oficial de la Generalitat Valenciana: 〈http://www.docv.gva.es/datos/2010/12/23/pdf/2010_13721.pdf〉.

\footnotetext{
${ }^{6}$ En el período en el que se realizó el trabajo de campo, seguía vigente el copago. Con el nuevo Gobierno autonómico, a principios de 2016, se eliminó parcialmente el copago, tanto el farmacéutico como el establecido para los centros de atención diurna.
} 
subsidiario que tienen las ayudas municipales. Y se subraya la subsidiariedad porque, una vez aprobada la Ley de la Dependencia, los trabajadores sociales municipales han diseñado su actividad de asistencia a los usuarios en función de los dictados de aquélla, lo que implica excluir a las personas dependientes, con la excepción de aquellos casos en que se ha solicitado la prestación por dependencia y todavía no se ha obtenido respuesta?.

Cuando una persona iba al Ayuntamiento a pedir una ayuda domiciliaria, en vez de explicarle que la podían dar ellos, pues le daban los 'papelitos' de la dependencia y la derivaban a Dependencia, para que lo pagara Consellería $\left(\mathrm{E}_{1}\right)$.

En cuarto lugar, al sistema se le atribuyen problemas de gestión que tienen nefastas consecuencias sobre el colectivo de personas dependientes. Una de las críticas destacadas por los entrevistados es el retraso en el reconocimiento del derecho al disfrute del servicio o la prestación económica concedida. Esta dilación desanima a los solicitantes del derecho, e incluso hay ocasiones en que la persona demandante o peticionaria fallece sin que se resuelva el caso. Se exponen algunos fragmentos discursivos que traen a colación este asunto:

Desastroso..., no tiene calificativo. Lo que en el Estado, en general, pero en la Comunidad nuestra [, en particular,] tenemos, no tiene nombre. Poco, mal, tarde, rateando; casi que tienes que mendigar y reclamar en mil instancias; que al final, la gente acaba cansada, agobiada, harta, para que te den una migaja después de no sé cuántos años, si te la dan... Vergonzoso, vergonzoso... $\left(\mathrm{E}_{2}\right)$.

No, nada... Yo ahí soy supercrítica..., creo que muchos recursos están llegando cuando los enfermos han fallecido, que hay muchas familias en las que su enfermo ha fallecido y siguen sin saber el grado nivel o ni han firmado el PIA [programa individual de atención]..., o al revés, que ha firmado el PIA, pero que nunca se beneficia realmente de eso... $\left(E_{7}\right)$.

Los rasgos generales del modelo de servicios sociales públicos de atención a la dependencia que acabamos de presentar constituyen un sistema poco satisfactorio. De ahí que las personas entrevistadas

\footnotetext{
7 Esto tiene una doble justificación: por una parte, el servicio de asistencia domiciliaria municipal no fue concebido para la prestación de una ayuda domiciliaria a personas en situación de dependencia, siendo sus beneficiarios otros grupos, como las personas mayores con dificultades de autonomía personal, las personas con algún tipo de discapacidad, las familias con menores en situación de riesgo social, y las familias con especiales problemas sociosanitarios; por otra parte, cuando los servicios sociales reciben a un usuario con necesidad de atención y valoran que se encuentra en situación de dependencia, se ven abocados a tramitar la documentación relativa a la Ley de la Dependencia. Por tanto, no pueden ofrecer el servicio de asistencia domiciliaria municipal a las personas dependientes, salvo en contadas ocasiones, como sucede cuando, solicitada la prestación por dependencia, ésta se demora, y se encuentran en fase de espera de concesión.
}

hagan reproches de carácter general, en los que critican a la Comunidad Valenciana por no ofertar un catálogo de servicios amplio y suficiente en materia de atención a la dependencia. El empeño del Gobierno regional ha consistido en priorizar la concesión de prestaciones económicas en detrimento de los servicios ${ }^{8}$, incluso siendo en algunos casos más recomendable, o incluso necesario, el uso de estos últimos. Algo que casa con la información ofrecida por el Servicio de Información del Servicio para la Autonomía y la Atención de la Dependencia (SISAAD), dependiente del Imserso:

Es una de las críticas más feroces que tiene esta ley, que nunca se ha apostado por los servicios, nunca... Si tú tienes recursos suficientes, adecuados, al final, puedes llevar a la persona, a tu mayor, a la persona que quieres mucho, a un centro de día, porque está bien atendido, que no te cuesta un dineral que no puedes pagar, y te vas un poco descargando de ese..., pero aquí, no te dan esa posibilidad... Aquí, yo creo que desde el principio no ha habido otra cosa [que la prestación económica para el cuidado en el entorno familiar] $\left(E_{2}\right)$.

¡Pero si es que los servicios públicos se están quejando de que no pueden garantizarlos! $\left(E_{6}\right)$.

Aquí, en el País Valencià, se está 'tirando' más por la prestación..., pero lo que está claro es que decantarse por las prestaciones se debe al hecho de que son más baratas para la Administración... $\left(E_{1}\right)$.

Ante este alud de críticas, a los informantes clave se les preguntó en las entrevistas sobre las medidas que deberían instrumentarse para remediar o paliar esta situación. Las respuestas se encaminaron en una doble dirección. Por una parte, indicaron que se deberían remover los obstáculos que impiden la conformación de un sistema distinto del actual, con provisión y prestación pública suficientes. Por otra, señalaron cuestiones más concretas, vinculadas con una correcta aplicación de la Ley.

En el primer plano, el de la conformación de un sistema plenamente público y con una oferta de servicios suficiente, todas las personas entrevistadas manifestaron que los cambios políticos ${ }^{9}$, y la consiguiente reorientación en el planteamiento de la Ley, eran necesarios:

Tiene que haber un cambio de Gobierno y que vean la necesidad que hay. Es una cuestión de prioridades [...]. La creación de dispositivos y de

${ }^{8}$ Y esto en contra de la Ley de la Dependencia, que establece el carácter prioritario de los servicios recogidos en el artículo 15, y sujeta a excepcionalidad la concesión de las prestaciones económicas.

${ }_{9}$ Nótese que el trabajo de campo se desarrolló en fechas coinci dentes con los comicios municipales y autonómicos de mayo de 2015 Todos los informantes se mostraron esperanzados en que un cambio en el color político del Gobierno autonómico comportaría cambios positivos en la atención a las personas en situación de dependencia. 
recursos mejoraría la posibilidad de retomar la vida laboral de las personas cuidadoras $\left(\mathrm{E}_{4}\right)$.

[...] la filosofía, el entendimiento..., desde ahí para abajo (a nivel político). Individualmente, cada uno podrá elegir lo que quiera o no, y culturalmente te traerá su mochila a cuestas; pero si no te ofrezco, da igual la mochila que traigas a cuestas de 'yo me lo quedaría en casa' o 'yo me lo llevaría a un centro' $\left(E_{5}\right)$.

Algún entrevistado también subraya que, en lo referente a los pilares que soportan las tareas de cuidado, la Administración pública no cuenta con el peso que le debería corresponder ${ }^{10}$, y que debería incrementarlo:

[...] debería cumplirse [la Ley], porque hay determinadas prestaciones y servicios que no se han puesto en marcha, como es la prestación por asistente personal..., la figura del asistente personal, el tema de la ayuda a domicilio... Yo creo que, con lo que hay, bien gestionado y poniéndolo bien en marcha, sería suficiente $\left(E_{2}\right)$.

¿Qué es lo que debería de cambiar? Ahora tenemos, en situación de dependencia, un sistema paralelo; entonces, habría que insertarlo dentro del sistema público. Consolidando el sistema público. Lo que no se puede crear son reinos... $\left(E_{8}\right)$.

A lo anterior se añade, en el plano de las reivindicaciones más concretas, la exigencia de una mayor agilidad en la resolución y prestación efectiva de los servicios y prestaciones:

Lo que debería cambiarse, lo primero, es la agilidad burocrática, porque tú tienes un dependiente hoy, y a ti no te sirve de nada que dentro de un año te den un PIA, porque tú, en ese año, tienes unas necesidades que, al final, están cargándose las familias $\left(E_{7}\right)$.

En esta misma línea, se señala la necesidad de avanzar en el efectivo cumplimiento de la Ley y la puesta en funcionamiento de algunos servicios que en el País Valenciano no han tenido lugar, especialmente el servicio de asistencia domiciliaria propio del catálogo recogido en la Ley de la Dependencia. En su lugar, se ha optado por conceder la prestación económica vinculada al servicio. De esta forma, el usuario debe elegir entre un listado de entidades autorizadas y, posteriormente, entregar periódicamente la factura a la Administración como prueba de que la cuantía percibida está siendo

${ }^{10}$ Se trata de un elemento especialmente importante en comunidades autónomas como el País Valenciano, en la que el esfuerzo en gasto social es claramente insuficiente, de los más bajos de todo el Estado. Por ejemplo, para 2015, el gasto en servicios sociales es del orden del $5 \%$ del presupuesto total de la comunidad autónoma (cuando el promedio estatal es del 6,4\%), un gasto de 172 euros por habitante (frente a los 228 en el conjunto estatal) [Asociación Estatal de Directores y Gerentes en Servicios Sociales, 2015b]. empleada para contratar ese servicio. Según declaran algunos informantes, uno de los problemas que conlleva la concesión de esta prestación es que la Administración pierde el control sobre su buen uso, al no disponer de suficiente personal para realizar ese seguimiento. Según las estadísticas del Portal de la Dependencia, en el territorio valenciano, y para los años 2015 y 2016, estas prestaciones rondaban los 5.000 beneficiarios.

\subsection{Asunción de funciones por parte de asociaciones del tercer sector en relación con los servicios de ayuda a las personas en situación de dependencia}

Ante la falta de recursos públicos disponibles suficientes para las personas en situación de dependencia, la siguiente cuestión planteada en nuestro trabajo de campo se vinculaba con la posible asunción por parte de las asociaciones del tercer sector de la función de provisión de una parte de estos recursos, un fenómeno que se apunta en el informe del tercer sector de acción de 2015 (Ruiz Villafranca, 2015). A este respecto, nuestros informantes atestiguan que son las asociaciones de afectados las que están supliendo la insuficiencia de servicios públicos, aunque existan alternativas dentro del mercado. Acogerse a la posibilidad de contratar un servicio de atención a las personas en situación de dependencia requiere de una capacidad económica suficiente para la compra. Ello deriva en diferencias entre aquellos con alto poder adquisitivo y quienes no gozan de esta capacidad, con el agravio para las familias de menos recursos y sus dificultades para la contratación (Muñoz y Pitxer, 2016).

Una parte de las familias que no pueden acudir al mercado, y cuya necesidad no ha quedado cubierta por los servicios públicos, hallan en el tercer sector de acción social un balón de oxígeno:

Yo sí que creo que la asociación está haciendo un papel que debería estar haciendo el sector público, que es dar servicios como tal... Si hubiera todos los recursos necesarios, [...] si los ofreciera el sector público, los estaría dando el sector público, y no tendríamos por qué estar en eso [...] $\left(\mathrm{E}_{6}\right)$.

Desde luego. Si no existiera esa necesidad, la gente no se agruparía [en asociaciones] para hacer ese tipo de cosas. [...] El tercer sector va a cubrir todos los huecos que la sociedad no... ¿Y el mercado? El mercado lo cubre si tienes dinero... $\left(\mathrm{E}_{4}\right)$.

Ahora bien, las asociaciones cuentan con recursos insuficientes, y ello a pesar de su acceso a subvenciones y de la firma de convenios con la Administración. Esta situación se ha agravado con la política de recortes en gasto social, en especial a partir de finales de 2011, lo que, en cierta manera, ha estimulado una mejora en la profesionalización de la gestión de algunas asociaciones, y subrayando 
la importancia de las aportaciones de las personas asociadas y beneficiarias del servicio como vía de ingresos. Las personas entrevistadas han sacado a relucir ambas cuestiones, a las que dedicamos unos comentarios a continuación.

En primer lugar, cabe señalar que es cierto que los recursos de los que disponen las asociaciones del tercer sector están limitados, quedando supeditados a la concesión de subvenciones o a la firma de conciertos con la Administración pública (municipal o autonómica). En el primero de los casos, existe el problema de que las subvenciones no cubren la totalidad de los gastos del proyecto y, además, su pago no se efectúa a principios de año, corriendo a cargo de la asociación todos los gastos previos a que se les haga efectivo el abono por parte de la Administración ${ }^{11}$. La crisis ha afectado a estas asociaciones, como declara, para su caso particular, un entrevistado:

La financiación [de la asociación] ha variado mucho desde el año 2011, que es cuando al tercer sector [le] viene el tsunami de la crisis... Fue llegar septiembre del 2011, y es cuando empezamos a notar que ya no nos está llegando el dinero y que las convocatorias empiezan a fallar... $\left(\mathrm{E}_{5}\right)$.

[...], porque no llegan las subvenciones. Estos centros funcionan a partir de subvenciones que da la Conselleria, entonces, claro... $\left(\mathrm{E}_{1}\right)$.

En segundo lugar, no debemos olvidar las diferencias existentes entre asociaciones en cuanto a nivel de profesionalización en la gestión, un aspecto subrayado por algunos entrevistados. Algunas de las asociaciones han debido transformar su modus operandi, encaminándose a un modelo de gestión más empresarial, mientras que otras se han mantenido en su tradicional perfil de actuación, menos profesionalizado, lo que les impide o dificulta competir con empresas mercantiles:

Ése es un poco el cambio de modelo, o de estrategia económica, que ha hecho [la asociación] ( $\left.E_{5}\right)$.

[...] es que la gente también tiene que tener iniciativa. $Y$ aunque con esto no se gane dinero, sí se puede tener la misma mentalidad que un empresario y hacer que una cosa sea [...]. Si entrara gente con una verdadera mentalidad de

${ }^{11}$ El Síndic de Greuges, en su informe anual a Les Corts Valencianes de 2014, subraya este problema, concretando, a diciembre de $\mathbf{2 0 1 3}$, en más de 95 millones de euros la deuda de la Conselleria de Bienestar Social con entidades públicas y privadas que gestionan centros para mayores: "las demoras en los pagos obligan a las entidades a realizar operaciones financieras que suponen unos gastos difícilmente asumibles, máxime en los casos en que se trata de entidades sin ánimo de lucro. Las demoras en los pagos [...], unidas a la dificultad con la que se encuentran las entidades de lograr líneas de financiación de entidades bancarias, están provocando problemas muy importantes en la gestión de los centros, como por ejemplo, demora en pago a proveedores, demora en pago de las nóminas a los trabajadores..." (2014: 384). empresario, gestionando, con una buena gestión, pues todo se puede hacer que sea... Yo no digo que se gane dinero, pero sí que sea rentable... También se tienen que tener buenas ideas en la vida, no podemos dejar que todo el Estado nos... Aunque tengas tu subvención, ¿no? Ahora se está moviendo mucho la gente, y como las subvenciones no llegan, pues entonces están haciendo muchos festivales, muchas cosas para sacar dinero, y antes no se buscaba a lo mejor ni esa opción..., esperaban directamente la subvención $\left(E_{3}\right)$.

Yo he trabajado en asociaciones pequeñas también y subsisten muy mal. A base de cuotas de socios, y al final, de la imaginación que tengan..., de ideárselas para seguir funcionando... $\left(\mathrm{E}_{4}\right)$.

Como tercera cuestión, uno de los informantes saca a relucir el asunto de los conciertos con el tercer sector y denuncia eventuales arbitrariedades a la hora de proceder a su concesión o firma, en el sentido de que pueden haber quedado condicionados por factores de cariz político. Y no sólo eso, sino que incluso recalca la existencia de dos bloques diferenciados dentro del tercer sector, lo que le lleva a mantener una postura crítica con el bloque que comprende las asociaciones y entidades de mayor renombre y presupuesto. Sobre éstas, opina que actúan de modo predatorio en contra de los servicios públicos, y presentan un objetivo alejado de los principios inspiradores del tercer sector de acción social, siendo su preocupación principal el acceso a todas aquellas subvenciones que puedan aparecer. Por el contrario, sí alaba a esas otras asociaciones del tercer sector que actúan como verdaderos representantes de los intereses de los afectados, independientemente del colectivo con el que trabajen ${ }^{12}$.

En cuarto lugar, nos vemos obligados a ir más allá de los conciertos para descubrir cómo la política de recortes del gasto público, particularmente intensa en el gasto social, se halla en la base tanto de este papel del tercer sector de acción social como de las aportaciones financieras de las familias para completar los ingresos procedentes de subvenciones y conciertos. En efecto, existe una relación causa-efecto entre la política de recortes en partidas sociales, de un lado, y la mayor actividad de organizaciones del tercer sector de acción social, de otro, algo que tiene lugar a partir de 2011 (Ruiz Villafranca, 2015). De hecho, el informe de entidades del tercer sector de acción social (ibídem) constata el doble campo de actuación de estas entidades: atención directa, por una parte; y asesoramiento e información, por otra. También se afirma que, con los recortes, se ha intensificado el esfuerzo en el primero de los campos, todo esto con menos recursos. Esta

${ }^{12}$ La citada arbitrariedad, según los entrevistados, no sólo, ni principalmente, parece tener lugar en el tercer sector, sino también en organizaciones de corte mercantil. A este respecto, en algunas entrevistas manifestaron tener constancia de irregularidades en la concesión de los conciertos, en concreto, con algunos grupos empresariales dedicados a la atención residencial. 
última deriva no siempre es apreciada, a tenor de las respuestas de ciertos entrevistados. Así, por ejemplo, en una de las entrevistas se expresa que las asociaciones no deberían tener como finalidad la prestación de servicios que corresponden a la Administración, sino configurarse como un espacio de confluencia entre sus miembros:

[...] como mucho, la asociación podría existir, ¿por qué no?, como punto de encuentro, que ésta surge así [...] lo que debería verse en la asociación, es decir, no dejar de existir, ser un punto de encuentro, pero que todos los recursos necesarios los ofreciera quien los debe ofrecer, que es la Administración pública $\left(\mathrm{E}_{6}\right)$.

[...] como pueden ser asociaciones de padres que han visto que no había plazas y que ellos mismos, a través de una ayuda, de una subvención, un préstamo, han creado su propio centro de día... $\left(E_{3}\right)$.

Con todo, y poniéndose en la situación de los socios, cabe decir que contar con recursos para la prestación de servicios ya no sólo depende de subvenciones y conciertos, sino que las personas asociadas deben realizar aportaciones periódicas para el mantenimiento de la asociación, aportaciones que suponen, en definitiva, un desembolso económico que no todas las familias pueden realizar. Por lo tanto, un servicio que inicialmente debería ser prestado por la Administración pasa a ser procurado por el tercer sector y cofinanciado por los propios usuarios:

[Las asociaciones] han creado su propio centro de día, y estos centros tienen una cuota asociativa $\left(E_{3}\right)$.

[...] cuotas, aportaciones de los usuarios; es prestación de servicios que ofrecemos, que es venir todas las mañanas, hacer actividades de promoción de la autonomía personal, y ellos aportan unos $x$ euros $\left(E_{5}\right)$.

Yo he trabajado en asociaciones pequeñas también y subsisten muy mal. A base de cuotas de socios, y al final, de la imaginación que tengan..., de ideárselas para seguir funcionando... $\left(\mathrm{E}_{4}\right)$.

Incluso en el caso de no ser socio, cabe la posibilidad de que exista algún convenio o concierto entre la Administración y la asociación, de tal forma que una persona en situación de dependencia acabe recibiendo los servicios en esta última, pagando parcialmente el coste del servicio:

Respuesta: Nosotros tenemos convenio con Ayuntamiento y subvención de Conselleria. El convenio con el Ayuntamiento son 25 plazas, a 21,52 euros/día [...]. Y esos 21,52 euros es lo que paga el usuario, y de esos 21 [euros] a lo que cuesta el centro de día en coste real, lo paga el Ayuntamiento con una subvención. Es un concierto, como un colegio concertado.
Pregunta: Pero entonces ¿qué paga el usuario?

Respuesta: 21,52 euros/día, que es lo mismo que pagaría en un centro municipal (E7).

Lógicamente, tras el recorrido realizado, resulta evidente que las familias con menos recursos y que no son beneficiarias ni de servicios ni de prestaciones públicas también pueden quedar excluidas de la atención por parte del tercer sector de acción social. De ahí que, llegados a este punto, se les preguntara a las personas entrevistadas qué solución les quedaba a las personas dependientes y a sus familias cuando no disponían de renta suficiente para hacer frente al pago requerido en el tercer sector de acción social. Su respuesta es que se ven obligadas a buscar otra vía que permita satisfacer esta necesidad. En este caso, caben dos posibilidades: que la familia opte por la contratación de una persona para prestar el servicio en el seno del hogar, frecuentemente en situación irregular; o el cuidado no profesionalizado brindado por la propia familia.

\section{Conclusiones}

Tras el estudio realizado, que incluye aportaciones fundamentales por parte de informantes clave, pueden extraerse algunos resultados que permiten esclarecer los problemas que acucian a las personas en situación de dependencia y a sus familias. La identificación de los distintos ámbitos de prestación de servicios de atención a la dependencia, la participación del sector público en la provisión (y, con menor frecuencia, en la prestación) de aquéllos, la existencia de opciones ideológicas en los procesos de decisión pública, el concurso simultáneo de distintos niveles de gobierno en las intervenciones relativas a los cuidados, la importancia de la proximidad tanto del decisor público como de las empresas y entidades que prestan el servicio en el campo de los servicios sociales, la convivencia de distintos perfiles de empresas y organizaciones que prestan estos servicios, así como la existencia de unidades familiares con condiciones socioeconómicas muy distintas son ingredientes fundamentales para abordar el análisis propuesto.

Con este trasfondo, cabe destacar los siguientes resultados:

- Hay una cierta duplicidad relativa a los servicios de atención a la dependencia, al coexistir unos mismos servicios tanto en el ámbito municipal como en el autonómico, lo que da cuenta de un escaso grado de coordinación entre niveles de gobierno.

- Los servicios sociales públicos son claramente insuficientes para cubrir las necesidades y demandas de las personas en situación de dependencia; y en la prestación, la Administración recurre con mucha frecuencia a la externalización del servicio correspondiente. 
- Existe una alta carga burocrática y unas demoras excesivas tanto a la hora de conceder la prestación como de disfrutarla, lo cual desanima a los afectados. Además, estas demoras han llevado parejas que algunos solicitantes falleciesen antes de que se les reconociese la situación de dependencia, o disfrutasen del servicio o prestación que les correspondía.

- Como consecuencia del déficit en los servicios públicos, es el tercer sector, especialmente a través de asociaciones de afectados, el que está supliendo las necesidades del colectivo de personas en situación de dependencia y ‘aliviando' de esta ‘carga' u obligación a la Administración. Esta actividad, que ya venía de antaño, ha visto aumentar su demanda, generando una mayor presión hacia el tercer sector en cuanto a la respuesta a estas necesidades. Todo ello, sin que se abandone el recurso a los cuidados no profesionalizados en el ámbito doméstico, a la mercantilización dentro de la economía informal o a las empresas de corte mercantil. Y aunque la labor del tercer sector merece ser destacada, también es cierto que no todas sus entidades parten de una misma situación, al existir diferencias entre aquellas dotadas de mayor profesionalidad en su gestión y aquellas con un perfil más amateur. Estas últimas presentan mayores dificultades para competir con las más profesionalizadas y con las organizaciones con ánimo de lucro. Igualmente, esta asunción también conduce a que la Administración vea justificada su dejación de funciones en cuanto a servicio público plenamente dicho, al escudarse en la concesión de subvenciones y conciertos en favor de las asociaciones del tercer sector o de empresas capitalistas.

Por otra parte, ya sea cubierto por las asociaciones del tercer sector de acción social o por entidades lucrativas del sector mercantil derivadas por la Administración pública, el servicio prestado no resulta gratuito para las personas en situación de dependencia. En el primero de los casos, contar con recursos para la atención de sus miembros exige no sólo la concesión de subvenciones para los programas solicitados, sino también el desembolso de cuotas periódicas por parte de sus socios. Para el segundo de los casos, la concesión del servicio de atención a las personas dependientes a través de organizaciones con ánimo de lucro - sector mercantil- no supone tampoco la exención de pago alguno, puesto que las aportaciones públicas sólo cubren una parte del coste, debiendo el usuario aportar el resto.

En definitiva, no ha habido una política tendente a ofrecer un servicio público e integral de atención a las personas en situación de dependencia. En este sentido, la Administración pública se 'vacía' (si es que en algún momento tuvo un contenido más o menos amplio), al no encargarse de la prestación de servicios y efectuar principalmente funciones de financiación y control (y esto, sólo de manera parcial). Son las empresas de corte mercantil o las organizaciones del tercer sector, junto con la sempiterna institución familiar -y ésta especialmente- quienes asumen la prestación de cuidados al colectivo, dándose muestras de esa recalibración o reequilibrio del Estado del bienestar en la que el rol del Estado no cumple con las expectativas de verdadero servicio público. Esta situación deriva de una clara opción política por parte de los Gobiernos del Partido Popular al frente del Ejecutivo autonómico, en el poder cerca de veinte años. Una opción que ha consistido en adelgazar el Estado del bienestar en su ámbito de actuación y ser la punta de lanza en pro del mercado, laminando áreas como la educación, la sanidad y los servicios sociales. Esta laminación en los servicios sociales tiene como principales perjudicados a aquellos usuarios y familias que no pueden costearse el servicio. La estrategia se ha intensificado a partir del deterioro de la situación económica desde 2008, lo que ha conducido a que sea la esfera familiar, y especialmente la mujer, la que ha visto reforzada su posición central como agente proveedor de cuidados a las personas en situación de dependencia. A su vez, queda patente la traslación desde la mercantilización previa a la crisis hasta la desmercantilización/ refamiliarización de los cuidados posterior a ésta.

Merece la pena, pues, prestar la atención oportuna a las decisiones que va tomando el nuevo Gobierno autonómico de corte progresista, y en qué medida éstas van a subvertir las decisiones adoptadas a lo largo de dos décadas de gobierno conservador en el País Valenciano. Será necesario contrastar si este nuevo rumbo va a contar con el tiempo suficiente para revertir los perjuicios ocasionados por el Gobierno anterior. Por el momento, y ya con más de un año en el poder, el nuevo Consell autonómico ha dado muestras de voluntad de afrontar el reto, que se han traducido en ligeros cambios en beneficio del colectivo de personas dependientes. La dirección es la adecuada, pero los cambios resultan todavía claramente insuficientes. 
ASOCIACIÓN ESTATAL DE DIRECTORAS Y GERENTES EN SERVICIOS (2015a): "Una ley innecesaria, de motivos espurios y efectos perversos", pág. 2 [ [http://directoressociales.com/images/ documentos/novedaddiscusion/RELATORIO_ DE_PONENCIA_LRSAL_FUENLABRADA.pdf $>$ ].

- (2015b): "El gasto social por comunidades autónomas. Educación, Sanidad y Servicios Sociales" (nota de prensa) [khttp://www.directoressociales. com/images/prensa/Ranking_CCAA_por_ recortes_y_gastos.pdf〉].

AYUNTAMIENTO DE VALÈNCIA: DEPARTAMENTO DE BIENESTAR SOCIAL, EDUCACIÓN Y DEPORTE (2016): “Memorias” [khttp://www.valencia. es/ayuntamiento/bienestarsocial.nsf/ vDocumentosTituloAux/Memorias?opendocum ent\&lang=1\&nivel=11>].

BANYULS, J. (2014): “Determinantes de la crisis en España: dinámica económica reciente y políticas públicas", Anuario IET de Trabajo y Relaciones Laborales, n- 2, págs. 79-90 [khttps://doi. org/10.5565/rev/aiet.32>].

BARBIERI, N.; y GALLEGO, R. (2015): “El despliegue de la Ley de Dependencia en el País Vasco y la Comunidad de Madrid (2007-2012): el margen de la autonomía política”, Zerbitzuan, n응, págs. 93-111 [<https://doi.org/10.5569/11347147.60.07)].
BETTIO, F.; SIMMONAZI, A.; y VILLA, P. (2006): “Change in care regimes and female inmigration: The 'care drain' in the Mediterranean", Journal of European Social Policy, vol. 16, nํㅜ 3 , págs. 271-285.

CASTLES, S.; y MILLER, M. (1993): The Age of Migration. International Population Movements in the Modern World, Londres, Macmillan.
CHAVES, R.; y MONZÓN, J. L. (2003): “La economía social y la política económica”, en CHAVES, R.; MONZÓN, J. L.; y SAJARDO, A., Elementos de economía social. Teoría y realidad, València, Universitat de València, págs. 7-26.

COLECTIVO IOÉ; y FERNÁNDEZ, M. (2010): Encuesta Nacional de Inmigrantes 2007: la situación de la inmigración en España, Madrid, Observatorio Permanente de la Inmigración; Ministerio de Trabajo e Inmigración.

DA ROIT, B.; y WEICHT, B. (2013): “Migrant care work and care, migration and employment regimes: $A$ fuzzy-set analysis", Journal of European Social Policy, vol. 23, ํㅜㄷㅗ. págs. 469-489.

DAATLAND, S. O. (2015): “Cuidados de larga duración en Noruega: legados, tendencias y controversias", en MORENO FUENTES, F. J.; y DEL PINO, E. (coords.). Desafíos del Estado del Bienestar en España y Noruega. Nuevas políticas para atender a nuevos riesgos sociales, Madrid, Tecnos, págs. 31-53.

DALY, M.; y LEWIS, J. (2000): “The concept of social care and the analysis of contemporary welfare states", British Journal of Sociology, vol. 51, $\mathrm{n}-2$, págs. 281-298.

DEL PINO, E. (2013): “The Spanish Welfare State from Zapatero to Rajoy: Recalibration to retrenchment", en BOTTI, A.; y FIELD, B. N. (eds.), Politics and Society in Contemporany Spain: From Zapatero to Rajoy, Basingstoke, Palgrave Mcmillan, págs. 197-216.

EDIS, EQUIPO DE INVESTIGACIÓN SOCIOLÓGICA (2012): Anuario del Tercer Sector de Acción Social en España 2012, Fundacion Luis Vives [khttp:// www.luisvivesces.org/upload/95/52/2012_ anuario_tsas.pdf)]. 
ENVEJECIMIENTO EN RED (2015): “Estadísticas sobre residencias: distribución de centros y plazas residenciales por provincia. Datos de junio de 2015", serie Informes en Red, no 13 Madrid, CSIC [ /http://envejecimiento. csic.es/documentos/documentos/enredestadisticasresidencias2015.pdf $>$ ]

EQUIPO NORSPAN (2015): "Los nuevos riesgos sociales y las reformas del Estado del Bienestar", en MORENO FUENTES, F. J.; y DEL PINO, E. (coords.), Desafíos del Estado del Bienestar en España y Noruega. Nuevas políticas para atender a nuevos riesgos sociales, Madrid, Tecnos, págs. 11-29.

ESPAÑA (2015): "Ley 43/2015, de 9 de octubre, del Tercer Sector de Acción Social”, Boletín Oficial del Estado, no 243, 10-10-2015, págs. 94.84494.852 [rhttp://www.boe.es/buscar/doc. php?id=BOE-A-2015-10922〉].

- (2013): “Ley 27/2013, de 27 de diciembre, de Racionalización y Sostenibilidad de la Administración Local”, Boletín Oficial del Estado, n- 312, 30-12-2013, págs. 106.430106.473 [/https://www.boe.es/diario_boe/txt. php?id=BOE-A-2013-13756>].

- (2006): “Ley 39/2006, de 14 de diciembre, de Promoción de la Autonomía Personal y Atención a las Personas en Situación de Dependencia", Boletín Oficial del Estado, no 299, 15-12-06, págs. 44.142-44.156 [<http://www.boe.es/ diario_boe/txt.php?id=BOE-A-2006-21990〉].

FANTOVA, F. (2015): “Crisis de los cuidados y servicios sociales", Zerbitzuan, no 60, págs. 49-62. ['https://doi.org/10.5569/1134-7147.60.04'].

FEDERACIÓN VALENCIANA DE MUNICIPIOS Y PROVINCIAS (2016): "Convocatoria de ayudas a las entidades locales valencianas para la financiación de los gastos de personal derivados del funcionamiento de los servicios municipales de atención a las personas en situación de dependencia en el ejercicio 2011", Diario Oficial de la Comunitat Valenciana, no 6.423, 23-12-2010, págs. 46.426-46.454 [<http://www.docv.gva.es/datos/2010/12/23/ pdf/2010_13721.pdf)].

FLAQUER, L.; PFAU-EFFINGER, B.; y ARTIAGA, A. (2014): "El trabajo familiar de cuidado en el marco del estado del bienestar", Cuaderno de Relaciones Laborales, vol. 32, № 1, págs.11-32.

FUNDACIÓN FOESSA (2014): VII Informe sobre exclusión y desarrollo social en España, Madrid, Fundación Foessa; Cáritas Española [<http://www. foessa2014.es/informe/uploaded/descargas/ VII_INFORME.pdf>].

GALLEGO, R.; GOMÀ, R.; y SUBIRATS, J. (2005): "Spain: From state welfare to regional welfare?", en MCEWEN, N.; y MORENO, L. (eds.), The Territorial Politics of Welfare, Abingdon, Routledge, págs.103-123.

GALLEGO, R.; y SUBIRATS, J. (2011): “Regional welfare regimes and multi-level governance", en GUILLÉN, A. M.; y LEÓN, M., The Spanish Welfare State in European Context, Surrey, Ashgate, págs. 97-117.

GARCÍA SAINZ, C. (ed.) (2011): Inmigrantes en el servicio doméstico, Madrid, Talasa.
GUILLÉN A. M.; y LEÓN, M. (2011): “Introduction”, en GUILLÉN, A. M.; y LEÓN, M., The Spanish Welfare State in European Context, Surrey, Ashgate, págs. 1-16.

GUILLÉN, A. M.; GONZÁLEZ-BEGEGA, S.; y LUQUE, D. (2015): "Austeridad y ajustes sociales en el sur de Europa. La fragmentación del modelo de bienestar mediterráneo", Revista Española de Sociología, nํ2 25, págs. 1-12.

HOMS, O. (2009): Los retos del Tercer Sector ante la crisis, Madrid, Fundación Luis Vives.

IMSERSO (2016): "Sistema para la Autonomía y Atención a la Dependencia” [<http://www.dependencia. imserso.es/dependencia_01/>].

LEÓN, M. (2010): “Migration and care work in Spain: The domestic sector revisited", Social Policy and Society, vol. 9, noํ 3, págs. 409-418.

LEÓN, M.; y PAVOLINI, E. (2014): “'Social investment' or back to 'familism': The impact of the economic crisis on family and care policies in Italy and Spain", South European Society and Politics, vol. 19, no 3, págs. 353-359.

LEÓN, M.; RANCI, C.; y ROSTGAARD, T. (2014): “Pressures towards and within universalism: Conceptualising change in care policy and discourse", en LEÓN, M. (ed.), The Transformation of Care in European Societies, Londres, Palgrave McMillan, págs. 11-33.

MARBÁN, V. (2016) "Estrategias de desarrollo del Tercer Sector de Acción Social en la postcrisis: ¿novedad o adaptación?", Revista Española del Tercer Sector, no 33 , págs. 141-162.

- (2011): "Los actores sociales en el sistema de dependencia español”, Cuaderno de Relaciones Laborales, $\mathrm{n}-1$, págs. 69-91.

- (2008): "El papel del Tercer Sector en la atención a la dependencia”, en PÉREZ ÁLVAREZ, M. Á.; y LÓPEZ, M. A. (coords.), El tratamiento jurídico civil de la dependencia. Actas del Congreso celebrado en A Coruña. 8-9 de noviembre de 2007, Universidade da Coruña, Servizo de Publicacións, págs. 87-99.

MARTÍNEZ BUJÁN, R. (2014): “Los modelos territoriales de organización social del cuidado de personas mayores en los hogares", Revista Española de Investigaciones Sociológicas, $\mathrm{n} \times \mathbf{0}$ 145, págs. 99-126.

- (2011): "La reorganización de los cuidados familiares en un contexto de migración internacional", Cuadernos de Relaciones Laborales, vol. 29, no 1 , págs. 93-123.

MARTÍNEZ-MARTÍNEZ, L.; y UCEDA-MAZA, F. X. (2015): “Las nuevas leyes de Servicios Sociales: propuesta para una nueva Ley de Servicios Sociales en la Comunitat Valenciana", en LLUCH, E.; ESTEVE, E.; y HORTAL, B. (eds.), ¿Recuperación? Enfoque agregado versus enfoque de la privación. Análisis y perspectivas Comunitat Valenciana 2015, Observatorio de la Investigación sobre Pobreza y Exclusión de la Comunidad Valenciana, págs. 96-137 [<http://www.foessa. es/publicaciones_download.aspx? $|d=5154\rangle]$.

MONTALBÁ, C. (2013a): “La crisis económica. Excusa para el entierro de un sistema de protección social que atiende situaciones de dependencia", Arxius de Sociologia, $\mathrm{n}^{0} \mathbf{2 9}$, págs. 7-18. 
- (2013b): “Aplicación del sistema de promoción de la autonomía personal y atención a personas en situación de dependencia en la Comunitat Valenciana: efectos sobre el ejercicio del derecho social", Alternativas, $\mathrm{n} \div \mathbf{0} 20$, págs. 163-186 [<https://doi.org/10.14198/ ALTERN2013.20.09>]

MONZÓN, J. L. (2006): “Economía social y conceptos afines: fronteras borrosas y ambigüedades conceptuales del Tercer Sector”, CIRIECEspaña. Revista de Economía Pública, Social y Cooperativa, nํ5, págs. 9-24.

MORENO, L. (2015): “La europeización del bienestar social en España”, en TORRES ALBERO, C. (ed.), España 2015. Situación social, Madrid, CIS, págs. 1.031-1.041.

MORENO, L. et al. (2014): Los sistemas de bienestar europeos tras la crisis económica, Madrid, Programa Eurosocial.

MORENO FUENTES, F. J. (2015): “Retos y reformas de las políticas de cuidado de larga duración en España", en MORENO FUENTES, F. J.; y DEL PINO E. (coords.), Desafíos del Estado del Bienestar en España y Noruega. Nuevas políticas para atender a nuevos riesgos sociales, Madrid, Tecnos, págs. 55-80.

MUÑOZ, Ó. (2015): “El declive de la Ley de la Dependencia. Familismo implícito y oportunidad perdida en la profesionalización de los cuidados", Encrucijadas. Revista Crítica de Ciencias Sociales, $\mathrm{n}$ - 10 [<http://www.encrucijadas.org/ index.php/ojs/article/view/153>].

MUÑOZ, Ó.; y PITXER, J. V. (2016): “Los cuidados en un contexto de crisis económica. El caso del Àrea Metropolitana de València”, Inguruak, n으, págs. 102-121. [<http://inguruak.eus/index. php/inguruak/article/view/35/>].

NALDINI, M.; y GUERRERO, T. (2009): “Families, markets and welfare states: The Southern European model" (comunicación en congreso), $7^{\text {th }}$ ESPANET Conference: 'The future of the welfare state: Paths of social policy innovation between constraints and opportunities', Urbino, 17-19 septiembre [<http://www.espanet-italia.net/ conference2009/paper2/3-Jurado-Naldini. $\mathrm{pdf}\rangle]$

PFAU-EFFINGER, B. (2014): “New policies for caring family members in European welfare states", Cuadernos de Relaciones Laborales, vol. 32 , no 1, págs. 33-48 [<https://revistas.ucm.es/ index.php/CRLA/article/view/44712/>].

RANCI, C.; y PAVOLINI, E. (2015): "Not all that glitters is gold Long-term care reforms in the last two decades in Europe", Journal of European Social Policy, vol. $25, \mathrm{n}^{-} \mathrm{3}$, págs. $270-285$.

RAZAVI, S. (2007): The Political and Social Economy of Care in a Development Context: Conceptual Issues, Research Questions and Policy Options, serie Programa Género y Desarrollo, nํㅜ 3, Ginebra, Instituto de Investigaciones de las Naciones Unidas para el Desarrollo Social [<http://www. unrisd.org/80256B3C005BCCF9/\%28httpAuxP ages $\% 29 / 2$ DBE6A93350A7783C12573240036D 5Ao/\$file/Razavi-paper.pdf>].

RODRÍGUEZ CABRERO, G. (2016): “La gran depresión y su impacto en las políticas sociales", Revista Española del Tercer Sector, nº 33, págs. 17-46.

- (2011a): "The consolidation of the Spanish welfare state (1975-2010)”, en GUILLÉN, A. M.; y LEÓN, M. The Spanish Welfare State in European Context, Survey, Ashgate, págs. 17-38.

- (2011b): "Políticas sociales de atención a la dependencia en los regímenes de bienestar de la Unión Europea", Cuadernos de Relaciones Laborales, vol. 29, nº. 1, págs. 13-42 [<http://revistas.ucm. es/index.php/CRLA/article/view/36184/>].

- (2005): “Los retos del Tercer Sector en España en el espacio social europeo: especial referencia a las organizaciones de acción social”, Revista Española del Tercer Sector, nº 1, págs. 63-94.

RODRÍGUEZ ENRÍQUEZ, C. (2015): “Economía feminista y economía del cuidado", Nueva Sociedad, no 256, págs. 30-44.

RUIZ VILLAFRANCA, R. (dir.) (2015): El Tercer Sector de Acción Social en 2015: impacto de la crisis, Plataforma de ONG de Acción Social; Plataforma Tercer Sector [<http://www.plataformaong.org/ ciudadaniaactiva/tercersector/estudio completo_el_TSAS_en_2015_impacto_de_la_ crisis.pdf $>$.

SAINSBURY, D. (1996): Gender, Equality and Welfare States, Cambridge, Cambridge University Press.

SANCHO CASTIELLO, M. (2006): “Las prestaciones sociales a la dependencia: situación y necesidades”, Documentación Social, nº 141, págs. 85-106.

SÍNDIC DE GREUGES DE LA COMUNITAT VALENCIANA (2014): "Informe a les Corts Valencianes" Síndic de Greuges de la Comunitat Valenciana [<http://www.elsindic.com/documentos/413_ MEMORIA2014\%20CAS.pdf $>$ ].

TORNS, T. (dir.) (2014): Nuevas profesiones para la organización social del cuidado, serie Estudios e Investigaciones, Instituto de la Mujer [<http:// ddd.uab.cat/record/126481>].

TORTOSA, M. Á. (2016): “La crisis y otros factores que empujan al replanteamiento de la atención a las personas mayores y dependientes en España”, Revista Española del Tercer Sector, no 33, págs. 91-110.

UNGERSON, C. (1999): “Personal assistants and disabled people: An examination of a hybrid form of work and care", Work, Employment \& Society, vol. 13, no 4, págs. 583-600.

VALLÉS, M. (1999): Técnicas cualitativas de investigación social. Reflexión metodológica y práctica profesional, Madrid, Síntesis.

VAN HOOREN, F. (2014): “Migrant care work in Europe: Variety and institutional determinants", en LEÓN, M., The Transformation of Care in European Societies, Basingstoke, Palgrave McMillan, págs.62-82. 